\title{
Being Successful in a Creative Profession: The Role of Innovative Cognitive Style, Self-Regulation, and Self-Efficacy
}

\author{
Flora Beeftink • Wendelien Van Eerde • \\ Christel G. Rutte $\cdot$ J. Will M. Bertrand
}

Published online: 21 April 2011

(c) The Author(s) 2011. This article is published with open access at Springerlink.com

\begin{abstract}
Purpose The purpose of this study was to test a model that proposes that innovative cognitive style and self-regulation (setting priorities, planning work activities, and monitoring time and task progress) are related to the selfreported success of architects. We investigated two aspects of the success: as designers and as business people. To this end, we examined the mediating role of self-efficacy in these relationships.

Data/Methodology/Approach We collected data using a web-based survey among 276 architects in the Netherlands. These were architects that either managed and/or owned a company, including freelance architects.

Findings Innovative cognitive style was related directly and indirectly, via design self-efficacy, to the self-rating of being a successful designer. Self-regulation, via self-efficacy, was indirectly related to being a successful designer, and directly related to being a successful businessperson. In addition, design success was related to success as a businessperson.

Implications This study shows that self-regulation at work is related to self-rated success in design and business. We regard self-regulation to be a form of actively
\end{abstract}

F. Beeftink · W. Van Eerde - C. G. Rutte - J. W. M. Bertrand

Eindhoven University of Technology, Eindhoven,

The Netherlands

W. Van Eerde $(\bowtie)$

The Amsterdam Business School, University of Amsterdam, Plantage Muidergracht 12, 1018 TV Amsterdam,

The Netherlands

e-mail: w.vaneerde@uva.nl

F. Beeftink · C. G. Rutte

Tilburg University, Tilburg, The Netherlands managing work tasks, identified as an increasingly important type of behavior at work.

Originality/Value This study is one of the first to investigate the self-regulation of creative professionals that included both design and business aspects. We focused on three aspects of self-regulation, and tested our model using structural equation modeling.

Keywords Self-regulation - Creative professions · Design work · Self-efficacy · Innovative cognitive style

\section{Introduction}

Economies increasingly depend on knowledge-based work and on creative work in particular (DeFillippi, Grabher, \& Jones, 2007; Thompson, Jones, \& Warhurst, 2007). Creative professionals, such as designers or architects, comprise a vital part of the workforce. A consensus about the importance of the creative industry for economies worldwide appears to have arisen (Flew \& Cunningham, 2010). For example, the number of jobs in the creative industry in the Netherlands increased by 33\% between 1996 and 2007, (ABF Research Kwartaalbericht Q1, 2008).

Research on creativity at work predominantly focused on the what factors influence novel and useful output (Shalley, Zhou, \& Oldham, 2004), where creativity is defined as the development of novel and potentially useful ideas (Amabile, 1996). Creativity requires a multitude of skills and abilities, including personal styles (Hennessey \& Amabile, 2010; Shalley et al., 2004). However, being successful in a creative profession also requires successful management of business aspects. This study provides a distinct contribution to the field of research regarding creativity in a work environment; in this regard we take a 
broader view on creative professions by considering both the creative and business aspects of the work. Accordingly, we have focused on self-regulation as a variable that is important to both aspects, as a way to flexibly adapt and adjust to dynamic circumstances.

Specifically, in a survey study among architects who own or manage businesses, we investigated to what extent an innovative cognitive style (which implies coming up with new ideas, rather than adapting to a status quo) and self-regulation (setting priorities, planning work activities, and monitoring progress) are related to the architects' selfperception of success as designers and business persons. Also, we examined the mediating role of design self-efficacy. Through our research, we have added to the existing body of work on creativity an examination of both creative and self-regulatory characteristics of individuals involved in design work. Although these aspects have been studied separately in different fields, both are necessary to be successful in a creative profession. In the following, we will present the proposed model (see Fig. 1). First, a brief overview of our theoretical framework is presented, and subsequently, each of the constructs of the model will be explained in more detail.

\section{Theoretical Framework}

Although creativity may be studied at different levels (Hennessey \& Amabile, 2010), we chose to focus on factors at the individual level of the designer. Knowing more about these factors may be helpful in the selection or training of individuals. This study aims to investigate the effect of three personal characteristics: (a) having an innovative cognitive style, (b) the use of self-regulation behaviors, and (c) the level of design self-efficacy.

Our theoretical framework is mainly based on the concept of self-regulation. When considering effectiveness at work as a process, adaptive self-regulation plays a major role (Tsui \& Ashford, 1994). Adaptive self-regulation emphasizes the importance of the dynamics involved in work processes. These work processes can be seen as continuous adaptation to changing circumstances through the use of feedback loops that involve standard-setting, displaying behavior, detecting discrepancies from the standard, and reducing discrepancies.

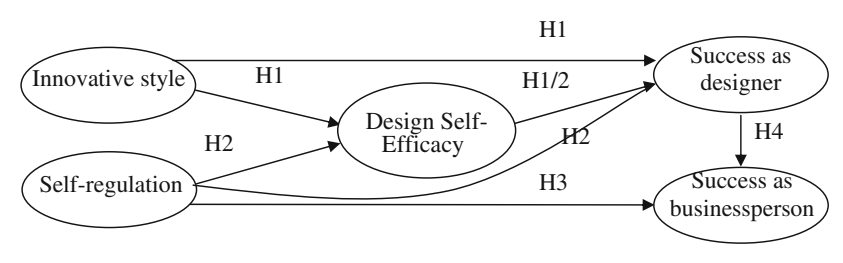

Fig. 1 Proposed conceptual model
Within a larger framework, we consider that performance is not only a matter of self-regulation, but also a function of ability and personal cognitive style. Individual differences may exist with respect to cognitive abilities and style that are particularly important in creative professions. Therefore, we included innovative cognitive style in the framework, so that the effect of self-regulation can be assessed over and above the effect of cognitive style.

The mediating mechanism that we examine is that of design self-efficacy. Specifically, repeated success in selfregulation is supposed to enhance self-efficacy, and selfefficacy may lead to the controlling actions and emotions needed for success in design and business.

We consider both self-evaluated success as a designer and success as a businessperson as outcome variables. Each of the variables in the model will be elaborated in the following.

\section{Innovative Cognitive Style}

We define a cognitive style as the way people perceive stimuli and how they use this information to guide their behavior (Hayes \& Allinson, 1998). One of the styles that is well known for its positive effect on creativity is having an innovative cognitive style (Shalley et al., 2004). An innovative cognitive style refers to a creative orientation to problem solving (Kirton, 1976, 1994). It is an individual's preferred way of gathering, processing, and evaluating information (Miron, Erez, \& Naveh, 2004). In our conceptualization, we follow Kirton (1976), who developed the Adaptor-Innovator framework, which differentiates individuals on the basis of adaptive and innovative cognitive styles. Whereas adaptors are characterized as doing things "better" (incremental improvements), innovators try to do things "differently" (radical improvements) (Kirton, 1994, p. 9). Although both characteristics may be assumed to be important in creative professions, the innovative style may be thought of as the more closely related to creativity of the two. Other conceptualizations, such as a three dimensional conceptualization (Cools \& Van den Broeck, 2007), were deemed less relevant and too extensive for this study.

\section{Self-Regulation}

Control theory of self-regulation suggests that task pursuit requires keeping track of task progress through repeated cycles of feedback loops. The information about task progress is gathered by monitoring task execution. A full feedback loop contains the following sequence of behaviors (Carver \& Scheier, 1998; Vancouver \& Day, 2005): (a) evaluating, prioritizing, and selecting tasks for completion, (b) planning for action, (c) executing the task, and 
(d) monitoring task progress (after which progress is evaluated and new decisions can be made with regard to task pursuit). Such a feedback loop is helpful in reflecting on what has been accomplished, and in developing plans for what still needs to be done. Through the feedback loop, managing and controlling the execution process can be managed, so that the course of action can be adjusted if necessary. Self-regulation can be seen as within-person processes that occur over time (Lord, Diefendorff, Schmidt, \& Hall, 2010), but individuals may also differ to the extent they engage in these behaviors.

\section{Design Self-Efficacy}

In addition to individuals' cognitive ability, and their ability to self-regulate their behavior, the confidence that the required activities can be executed is crucial (Bandura, 1977). Bandura (1982) states that exercising control over one's own behavior is not a matter of willpower but of the tools of personal agency and the self-assurance to use them effectively. By comparing personal standards versus performance, individuals can evaluate how satisfied they are with the outcome of the behavior. If standards and performance are closely matched, this leads to satisfaction and confidence in the performance. This in turn may help to sustain motivation, even if there is a discrepancy between the standard and performance a next time. Increasingly, more difficult goals can be set that help individuals to learn. As such, self-efficacy influences thought patterns, actions, and emotional arousal (Bandura, 1982). A lack of self-efficacy hinders task completion, and a high level of self-efficacy facilitates it.

Meta-analytic integrations of the research on self-efficacy have shown its relation to job performance (Judge \& Bono, 2001; Stajkovic \& Luthans, 1998) and job satisfaction (Judge \& Bono, 2001). One of the most important predictors of self-efficacy is the experience of success in past performance (Bandura, 1977). These experiences build a steady level of self-efficacy that is not easily altered by an occasional failure to complete a task.

In this study, we chose to focus on task-specific rather than general self-efficacy, i.e., design self-efficacy, or the extent to which a person feels confident to perform well on the design aspects of the job. This idea matches Bandura's original ideas on self-efficacy, in that self-efficacy is not general self-confidence, but needs to be considered for specific tasks. A person may feel very self-efficacious for one particular task, but less so in regards to other tasks.

\section{Professional Success}

Based upon our conversations with architects, we distinguished two aspects of performance: success as a designer and success as a businessperson. When an architect enjoys success as a designer, it means that the creative and technical aspects of that individual's work may be recognized, for example because the media devotes attention to the designs for a larger audience, or because prizes or awards are given for the designs. This in turn may lead to business success: satisfied customers, completed design projects, a higher income, and a good reputation. Although we see design success as a precondition for business success, it is possible for an architect, highly skilled in design, to fail to achieve success due to other reasons such organizational abilities, reliability, ability to work effectively in teams, etc. For example, when appointments are not kept, or when changes need to be made in later stages of the project. This inverse is also true. It is also possible that an architect enjoys business success without much design success. For example, providing a very good service to clients, without being recognized for the creativity of the designs is produced.

We think that the distinction between these aspects is useful, in that other types of demands are placed upon the individual to achieve success in these domains. Creative problem solving and technical skills are necessary for design success, while organizational knowledge and overall business acumen are required for business success. Furthermore, it is of interest to find out how much these domains are intertwined or separate within one individual.

A recent study (Oyedele \& Tham, 2007) provides some insight into the components of architectural performance from the viewpoint of customers. This study was exploratory in nature, and clients were asked to rate the importance of several aspects of architecture performance. A factor analysis revealed six factors. The most important factor was "management skills and ability". The next factor was identified as "design buildability". The other aspects involved quality, project communication, project integration, and client focus. We see similarities between the first two factors and Oyedele and Tham's (2007) study. Management skills and ability can be seen as parallel to success as a businessperson, and design buildability as parallel to success as a designer.

Another study (Ling, 2003) focused on performance theory to investigate which factors may be distinguished when project managers select architects to work with. Four factors were distinguished: task performance, contextual performance, reputation in a network, and price. The study compared project managers' ratings with those of architects. The study revealed that both parties have different ideas of what is important for effective cooperation. The items measuring "architect has a good reputation", "architect is creative and innovative", and "architect has a good project approach" received the highest ratings. 
These two studies show that different parties may focus on other aspects of performance. No previous study, as far as we are aware, addressed the factors architects themselves judged as most important to their success. Diamond and Moezzi (2002, p. 9) even remarked: "A constant problem in the design profession is that several players never learn whether their designs have been 'successful'and there is no commonly agreed on definition of what constitutes 'success'." Here, we focus on two aspects: their perception of how they perform as designers, and how they perform as businesspersons.

\section{Hypotheses}

We now present our hypotheses on innovative cognitive style, self-regulation, and self-efficacy for two outcomes, success in design and in business.

Based on the idea that radical improvements are needed for creative output, rather than incremental improvements, it is likely that cognitive innovators are better designers. Recent research has shown that being innovative and being adaptive are not opposites, but rather two independent aspects of an individual's cognitive style, and that an innovative cognitive style is predictive of creative performance (Goldschmidt, 1999; Miron et al., 2004; Tierney \& Farmer, 2004). This forms the basis of our first hypothesis.

We also acknowledge that there may be mediating variables involved, in particular self-efficacy in the area of design work. Individuals with an innovative style may also have had more positive past experiences with creative tasks. Since the level of self-efficacy of individuals is gradually built through past experiences (Bandura, 1977), designers with a more innovative style may also have higher levels of design self-efficacy. Self-efficacy has been found to be an important predictor of performance, including creative performance, such as measured by using originality ratings of products or ideas (cf. Gong, Huang, \& Farh, 2009; Jaussi, Randel, \& Dionne, 2007; Redmond, Mumford, \& Teach, 1993; Tierney \& Farmer, 2002). Hence, designers with a higher level of design self-efficacy are likely to perceive themselves as more successful designers. A higher level of self-efficacy enhances the persistence level and coping efforts of individuals when they encounter challenging situations (Bandura, 1977). Sustained efforts are often crucial to complete a creative task (Amabile, 1988; Tierney \& Farmer, 2002), and persistence may therefore be beneficial to design work. As a result, a higher level of self-efficacy may be related to being a more successful designer. Combining the proposed effects of innovative style on self-efficacy, and the effects of self-efficacy on being a successful designer, we hypothesize as follows:
Hypothesis 1 Design self-efficacy partially mediates the relation between innovative cognitive style and perceived design success.

Recently, awareness has arisen that not only the cognitive style or processes, but also the meta-cognitions that manage and control these processes are highly relevant to creativity (Isaksen \& Treffinger, 2004, pp. 92-95; Osburn \& Mumford, 2006). Meta-cognitions involve self-regulation behaviors such as planning and monitoring time and task progress (e.g., Peeters, Van Tuijl, Reymen, \& Rutte, 2007; Sonnentag, 1998), whereas self-regulation behaviors guide and support creative problem solving processes. The creative problem solving model of Isaksen, Dorval, and Treffinger (2000) includes creative cognitive processes (e.g., generating ideas) and a creative-process-management component that consists of activities such as "continuous planning, monitoring, managing, and modifying behavior during creative problem solving" (Isaksen \& Treffinger, 2004, p. 92). Several studies have confirmed the importance of self-regulation for designers. Individuals working in interdisciplinary design teams (Peeters et al., 2007) performed better when they displayed design creation behaviors (such as generating ideas and solutions) and design planning behaviors (such as planning time and keeping and adjusting schedules). Sonnentag (1998) studied software designers and compared high versus moderate performers. She found that high performers engaged in planning and monitored behaviors to a larger extent than average performers while engaging in a design task. Reflection is also important to the design process (Reymen et al., 2006). Creative tasks involve a high level of task uncertainty (Cropley, 1999). For example, in new product development projects the design activities are generally not fully known beforehand, and neither is the precise time known to design the new product (Van Oorschot, Bertrand, $\&$ Rutte, 2005). Therefore, it is difficult to make detailed plans (Britton \& Glynn, 1989). Thus, task progress should be monitored, and feedback regarding the progress should be used to make and adjust further plans. It is therefore to be expected that designers perform better when they have the tendency to regulate their design activities. Furthermore, self-regulation is related to self-efficacy because managing and controlling processes leads to the perception of being "in control" (Bandura, 1991). Goal setting theory has also incorporated the idea that self-regulation leads to goal achievement by means of a stronger sense of selfefficacy (Cools \& Van den Broeck, 2007; Locke \& Latham, 1990). In a longitudinal study (Claessens, Van Eerde, Rutte, \& Roe, 2004), planning behaviors of R\&D engineers were indeed related to the perception of being in control of time and to higher levels of job performance and job satisfaction. Similarly, we hypothesize that self-regulation is 
not only directly related to perceived design success, but also indirectly, via a heightened level of self-efficacy:

Hypothesis 2 Design self-efficacy partially mediates the relation between self-regulation and perceived design success.

As has been mentioned before, self-regulation provides the opportunity to manage and control design processes, but it is thought to be also important for business in general, where the quality, efficiency, and timeliness of work processes need to be monitored (Deming, 2000) Considering that adaptive self-regulation is seen as beneficial to performance (Tsui \& Ashford, 1994), we hypothesize the following:

Hypothesis 3 Self-regulation is positively related to perceived business success.

The last path in the model was to establish whether, and to what extent, perceived design success was related to perceived business success. We see these two domains as complementary in the profession of an architect. We take this idea even further and consider design success, which could be considered the core of an architect's job, as an important prerequisite for business success. That is why we modeled the path from design to business success (see Fig. 1). This implies a mediational chain, which we will also analyze. Primarily, we will test the following hypothesis:

Hypothesis 4 Perceived design success is positively related to perceived business success.

\section{Method}

Sample and Procedure

Developing architectural designs is a creative act (Goldschmidt, 1991), and therefore architects are generally perceived to be creative professionals (cf., Feist, 1998; Kirton, 1994; Unsworth, 2001). That is why we approached the Organization of Dutch Architects (BNA) to participate in our study. Invitations to participate in this study were sent out by email to approximately 2,100 members. One week later a reminder was sent. The response rate was $16.1 \%$, which is a moderate, but acceptable response rate for this type of study and respondents (Baruch, 1999). From the respondents, we selected those architects who were employers, or self-employed and running an one-person business or in a management position within an architectural firm $(n=276)$. The large majority of the participants were male $(90 \%)$, reflecting the male dominated nature of the profession, particularly in the role of manager or business owner. When we compare this to statistics on the profession in the Netherlands, it is lower than the average percentage of female architects and engineers over the past 10 years, 22\% (CBS, 2010). However, it is not clear which types of jobs were included in these general numbers, and we explain the lower percentage of women in the sample by the roles of manager/owner. The mean age of the sample was 45.5 years $(\mathrm{SD}=8.9)$, and the average work experience was 18.2 years $(\mathrm{SD}=9.3)$. On average, they worked $43.6 \mathrm{~h}$ per week $(\mathrm{SD}=10.7)$ of which they estimated they spent $31.3 \%(\mathrm{SD}=10.8)$ on design work.

\section{Measures}

Data were collected with an online questionnaire. All items were in Dutch. English scales were translated using a procedure of back and forth translation. All scales were scored on a 5-point Likert scale ranging from highly disagree (1) to highly agree (5). Cronbach's alphas for the scales are presented on the diagonal of Table 1.

\section{Demographic Background}

We included gender, age, and work experience as background variables.

\section{Innovative Cognitive Style}

We used the 4-item creativity subscale of the cognitive style measure of Miron, Erez, and Naveh (2004) to assess innovative cognitive style. This subscale is a short version of the innovation style subscale of the Adaption Innovation Inventory developed by Kirton (1976, 1994). An example item is: "I prefer tasks that enable me to think creatively".

Table 1 Summary of confirmative factor analyses for the self-regulation subscales

\begin{tabular}{llllllll}
\hline $\begin{array}{l}\text { Competing } \\
\text { models }\end{array}$ & $\chi^{2}$ & $\mathrm{~d} f$ & $\Delta \chi^{2}$ & $\begin{array}{l}\Delta \\
\mathrm{d} f\end{array}$ & RMSEA & GFI & CFI \\
\hline $\begin{array}{c}\text { One-factor } \\
\text { model }\end{array}$ & 375.59 & 65 & & & 0.13 & 0.83 & 0.81 \\
$\begin{array}{c}\text { Two-factor } \\
\text { model }\end{array}$ & 250.16 & 64 & $125.43 * * *$ & 1 & 0.11 & 0.87 & 0.87 \\
$\begin{array}{c}\text { Three-factor } \\
\text { model }\end{array}$ & 157.15 & 62 & $93.01 * * *$ & 2 & 0.08 & 0.94 & 0.92 \\
\hline
\end{tabular}

RMSEA root-mean-square error of approximation; GFI goodness of fit index; and $C F I$ comparative fit index

$n=276$

*** $P<0.001$, indicating a significant improvement over the previous model 


\section{Self-Regulation}

Self-regulation was measured with the following three subscales:

\section{Focusing on Work Priorities}

Three items from Tripoli's (1998) priority focus scale were used. An example item is: "I review my priorities before determining what design activities to work on next."

\section{Planning Work Time and Activities}

Tripoli's (1998) anchored planning scale was used (4 items). An example item is: "I usually develop time tables for most designs on which I am working."

\section{Monitoring Time and Task Progress}

The 6-item time monitoring scale of Claessens (2004) was used. An example item is: "While executing my design tasks, I regularly check whether there is progress."

To gain more insight into the structure of the overall self-regulation scale and its subscales, we performed confirmatory factor analyses using LISREL 8.80 (Jöreskog \& Sörbom, 2007). These showed that a three-factor model fitted the data best (see Table 1). The three means of the subscales were used as indicators in the measurement model. The factor loadings were $\lambda=0.61$ for priority focus, $\lambda=0.53$ for planning, and $\lambda=0.72$ for monitoring.

\section{Design Self-Efficacy}

We used the 8-item occupational self-efficacy scale of Schyns and Von Collani (2002), reworded for designers. An example item is: "When I am confronted with a problem in a design, I can usually find several solutions."

\section{Perceived Success as a Designer}

Although we were aware that self-reports might compromise the outcomes of the study somewhat, we were nevertheless interested in the judgment of the architects themselves also because in many cases it was impossible to obtain peer or supervisor ratings, as many of the respondents did not have those. We developed a 3-item scale, specifically focused on how the architect perceived a specific job outcome, related to design, and specifically, whether that would be perceived differently from having success in business. Some concurrent validity for this new scale was obtained through its relation with other information provided by the respondents: the number of their designs published in the daily press $(r=0.24, P<0.001)$ and the number of their designs published in architecture journals $(r=0.20, P<0.001)$.

\section{Perceived Success as a Businessperson}

To measure this variable we also developed a 3-item scale specifically for this study. Exploratory factor analysis, extracting orthogonally (varimax) rotated factors, provided a first step in validating the measurement of these two success measures (see Table 2). Second, confirmatory factor analysis showed that the two scales were separate factors (see Table 3), and could not be combined into one measure: The one-factor model did not fit the data; the twofactor model fitted the data. The improvement of two factors over one was significant, as indicated by the difference in $\chi^{2}$.

\section{Data Analysis}

The model was analyzed using structural equation modeling (SEM) by means of LISREL 8.80 (Jöreskog \& Sörbom, 2007). Each of the variables in Fig. 2 were included as a latent factor, and their corresponding items were modeled in the measurement model in the same analysis. Only the self-regulation factor was modeled by the three subscale mean scores of priority focus, planning, and monitoring, rather than the items.

\section{Results}

Means, standard deviations, and zero-order correlations among variables can be found in Table 4. This table shows that innovative cognitive style was not related to self-regulation and to success as businessperson, but was to selfefficacy and to success as designer. Self-regulation was related to self-efficacy and success as businessperson. Success as designer and success as a businessperson were related.

We used work experience as a control variable. No gender effects were found.

The test of the model shows that all of the suggested paths, except for one, were significant. The proposed model (see Fig. 2) fitted the data well $\left(\chi^{2} / \mathrm{d} f\right.$ ratio $=2.01$, $\mathrm{RMSEA}=0.05, \mathrm{CFI}=0.94$, and GFI $=0.90)$.

We found support for $\mathrm{H} 1$, as both the direct effect of innovative cognitive style, and the indirect effect of innovative cognitive style via design self-efficacy on perceived design success was found (Sobel test $=3.57, P<0.001$ ). Regarding H2, we only found the indirect effect of selfregulation via self-efficacy (Sobel test $=3.09, P<0.01$ ), not the direct effect that we also hypothesized, which implies full mediation. The total variance accounted for by 
Table 2 Factor loadings and eigenvalues for the rotated factor matrix of the success scales
The highest factor loadings are shown in boldface

$n=276$
Subscales with items

Factor

1

2

Success as designer

If I take into account my design work only, I see myself as a successful architect $\quad 0.10$

0.78

My design ambitions make me a successful architect

$0.01 \quad \mathbf{0 . 8 2}$

With respect to creativity, I am a successful architect

0.26

0.68

Success as businessperson

Business-wise, I am successful compared to other architects

$\mathbf{0 . 8 4} 0.19$

I am a successful architect thanks to my organizational abilities

$\mathbf{0 . 8 5} 0.04$

Looking at the financial side of it, I regard myself a successful architect $\quad 0.13$

Eigenvalues
Table 3 Summary of confirmative factor analyses for the success scales

\begin{tabular}{lrllllll}
\hline $\begin{array}{l}\text { Competing } \\
\text { models }\end{array}$ & $\chi^{2}$ & $\mathrm{~d} f$ & $\Delta \chi^{2}$ & $\Delta \mathrm{d} f$ & RMSEA & GFI & CFI \\
\hline $\begin{array}{l}\text { One-factor model } \\
\text { Two-factor model }\end{array}$ & 114.87 & 9 & & & 0.21 & 0.88 & 0.78 \\
\hline
\end{tabular}

RMSEA root-mean-square error of approximation; GFI goodness of fit index; and $C F I$ comparative fit index

$n=276$

*** $P<0.001$, indicating a significant improvement over the previous model

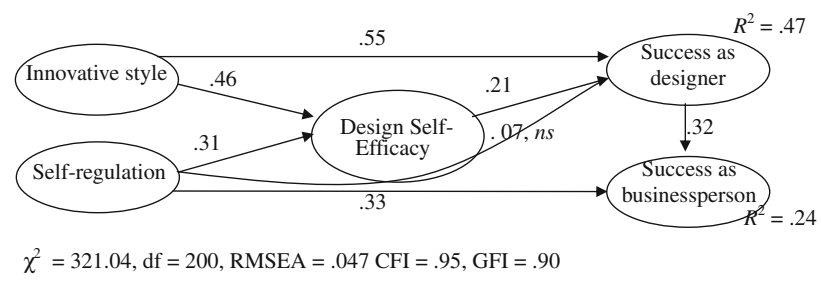

Fig. 2 Results for the structural equation model

the predictors of perceived design success was $47 \%$. We found a direct effect of self-regulation on success as a businessperson (H3). The relation between design success and success as a businessperson was also significant (H4). The predictors in the model accounted for $24 \%$ of the variance in success as a businessperson. Only one additional path may improve the structural equation model according to the modification index provided: from design self-efficacy to business success.

\section{Discussion}

The results of this study show that innovative cognitive style and self-regulation (setting priorities, planning work activities, and monitoring time and task progress) were related to perceived design success via design self-efficacy. Success as a designer, in combination with self-regulation was also related to success as a businessperson. Self-efficacy plays a key role in these relationships as a (partial) mediator in the relation between innovative cognitive style and self-regulation and success as a designer. These results were as hypothesized. However, there was no direct relation between self-regulation and perceived success as a designer, as we hypothesized.

In the past, research on creativity at work predominantly focused on the creative aspects of creative professions (Shalley et al., 2004). This study provides a distinct contribution to the literature about creativity at work, because it adopted a broader view on creative professions by including self-regulation and perceived success in both the creative and business aspects of the work. We think that our field study sheds some light on the relative importance of the creative aspect of the job. Although design work may be seen as the core and the most important aspect of an architect's job, the architects indicated that they only spend a minor portion of their work time on design work. In this study, time spent on design activities was not related to other variables in the study, nor did it moderate the relation between design and business success. Our model shows that both design and commercial activities are important aspects of the job, and many studies on creative professionals may have overlooked the large part that business takes in a creative profession. The model tested shows that the two domains are related, and that perceived business success is partially dependent on design success. Self-regulation appears to be relevant to both aspects.

A second contribution concerns the role of self-regulation behaviors in design work. Planning and monitoring creative work may sound as a contradictory to the "eureka" idea of sudden insight, or the right moment for inspiration. Yet, awareness is growing that self-regulation may be beneficial to creativity (Isaksen \& Treffinger, 2004). However, little research had been conducted to test the importance of self-regulation to creative output. 
Table 4 Descriptive statistics and zero-order correlations

\begin{tabular}{|c|c|c|c|c|c|c|c|c|c|c|c|}
\hline & & Mean & SD & 1 & 2 & 3 & 4 & 5 & 6 & 7 & 8 \\
\hline 1. & Self-regulation & 3.41 & 0.49 & $(0.81)$ & & & & & & & \\
\hline 2. & SR: priority focus & 3.69 & 0.68 & $0.67 * * *$ & $(0.71)$ & & & & & & \\
\hline 3. & SR: planning & 3.39 & 0.68 & $0.75 * * *$ & $0.32 * * *$ & $(0.70)$ & & & & & \\
\hline 4. & SR: monitoring & 3.47 & 0.48 & $0.83 * * *$ & $0.44 * * *$ & $0.38 * * *$ & $(0.74)$ & & & & \\
\hline 5. & Innovative cognitive style & 3.72 & 0.46 & 0.00 & 0.06 & 0.04 & -0.05 & $(0.65)$ & & & \\
\hline 6. & Design self-efficacy & 3.91 & 0.33 & $0.20 * * *$ & $0.21 * * *$ & $0.19 * * *$ & $0.12 *$ & $0.31 * * *$ & $(0.79)$ & & \\
\hline 7. & Business success & 3.21 & 0.65 & $0.20 * * *$ & $0.20 * * *$ & $0.18 * *$ & $0.27 * * *$ & 0.01 & $0.30 * * *$ & $(0.73)$ & \\
\hline 8. & Design success & 3.52 & 0.48 & 0.08 & 0.08 & 0.10 & 0.06 & $0.44 * * *$ & $0.29 * * *$ & $0.30 * * *$ & $(0.66)$ \\
\hline
\end{tabular}

$n=276$

$* P<0.05, * * P<0.01$, and $* * * P<0.001$

Exceptions are the studies of Peeters et al. (2007) and Sonnentag (1998) that provided support for the importance of planning and monitoring during the design process. Our study supports their findings, but shows specifically that the relation should be seen as mediated by design self-efficacy, as we did not find a direct relation between self-regulation and design success. This is indeed how goal setting theory would view the role of self-regulation in achieving goals: through heightened self-efficacy (Locke \& Latham, 1990).

A third contribution demonstrated that self-regulation was directly related to business success, over and above the relation between the success in design work and business success. This implies that professionals who focus on priorities, plan, and monitor do not only contribute to their perception of success in their design work, which actually forms only a minor part of the work in terms of time spent, but also to their success in business. This affirms the idea that adaptive self-regulation is important to performance in general (Tsui \& Ashford, 1994).

A fourth contribution of this study concerns the role of self-efficacy in creative work. We answered Shalley et al.'s (2004) call for more research on self-efficacy in creative work, and specifically, the need for more information on the relationship between self-efficacy and other personal characteristics, such as having an innovative cognitive style (pp. 946). Our results show that design self-efficacy plays a pivotal role between innovative cognitive style and success as a designer.

\section{Strengths and Limitations}

In addition to the contributions pointed out above, a first strength of our study was that it was conducted among a working population consisting entirely of creative professionals: architects. Moreover, our sample included individuals working in both large and small businesses. Often, for practical reasons, research on creativity at work is conducted in large organizations (cf., Amabile, Schatzel,
Moneta, \& Kramer, 2004; Hargadon \& Bechky, 2006; for an exception see: Tschang, 2007). This sample represents individuals working in organizations of different sizes, and it includes freelancers. These form an important part of the workforce, but are often not included in samples obtained in large companies.

Another large strength of this study is the use of structural equation modeling in our analyses. These sophisticated statistical analyses provide the opportunity to test hypotheses using a complete model. This is particularly interesting when models contain more than one outcome variable and when models contain paths via mediators (cf., Mathieu \& Taylor, 2006), both of which apply to our model. We also inspected the modification indices given in the analysis. Only an additional path between design selfefficacy and business success would improve the model. However, theoretically, we had no grounds to expect this, but within this sample, it was the case. Perhaps this is an indication that several outcomes may be affected by a specific type of self-efficacy.

Notwithstanding the contributions of our study, we should also point out some limitations. A first limitation is the use of self-reports. For some scales this may be less problematic, because these things can best be judged by persons themselves (e.g., the use of self-regulation behaviors or the level of self-efficacy). The self-rated success of architects as designers and businesspersons showed concurrent validity with more objective indicators, but these measurements would also have benefited from information from an additional source, such as supervisors or coworkers. This was difficult to obtain because many of the architects in our sample did not have direct coworkers or supervisors. Thus, our sample had the advantage of including architects working in smaller firms, but this also resulted in limitations with regard to the possibilities for collecting peer ratings. Business performance might have been assessed in terms of profit or revenues. However, these numbers would have been difficult to compare over 
the different types of architects. That is why we chose to use a scale to assess the relative success these professionals experienced, which may be good for the comparability, but we are aware that there may be some bias involved, for example, self-enhancement that may have caused the architects to see their achievements in a positive light. Actual creative output may differ from this subjective measure, as it is an interpretative element that may be influenced by personality, self-identity, or other factors. This may have consequences for the replication of the results when objective outcomes, or performance judged by others, would be used.

A second limitation of this study might be its moderate response rate. Non-response might have been relatively high because our sample included professionals, part of them with management tasks. This type of population tends to display lower response rates compared to, for example, samples from people working in education, or students (Baruch, 1999; Green, Boser, \& Hutchinson, 1998). Furthermore, reaching acceptable response rates has become more difficult because, in general, the willingness to participate in survey research has declined over the years (Baruch, 1999; Dey, 1997). Taking into account our sample's characteristics and the mode of responding (internet survey), our response rate can be considered acceptable (Baruch, 1999).

Third, the lower coefficient alphas for the scales measuring innovative cognitive style and perceived design success may be seen as a limitation. However, considering that only four or three items were used, we still think that the internal consistencies of the scales are acceptable. However, the stability of the results may suffer due to these low reliabilities, casting some doubt whether these results will be replicable in another sample. This may be a point to improve in the future use of these scales. The innovative cognitive style scale has been widely used before, and it may be just a fluctuation due to this particular sample. However, utilizing perceived success as a designer scale may need further development.

A fourth limitation of the study was that only self-efficacy for design work was included. Perhaps future research can add self-efficacy with respect to business aspects as well. This would provide a more balanced and complete view, and it would offer the possibility to assess the crossover effects from business self-efficacy to design success.

A final limitation is the cross-sectional design. This means that the causality of the relationships in our path model may be in the anticipated direction, but may also be in the opposite direction, or variables may be related reciprocally. This design may also have had an influence on the magnitude of the correlations, in that these may be somewhat inflated. However, the correlations do not appear to be overly high apart from those that should correlate highly because they refer to self-regulation.

\section{Suggestions for Further Research}

We suggest further investigating the process of self-regulation in creative work. Specifically, we recommend studying it over time, and in more detail. A think-aloud study may be a helpful method to investigate this. For example, a think-aloud study of Sonnentag (1998) provided interesting insights into the planning and monitoring activities of software designers during task execution. A think-aloud study of Fleck and Weisberg (2004) focused on cognitive creative processes, but not on self-regulation behaviors. A future think-aloud study could combine the studies of Sonnentag (1998) and Fleck and Weisberg (2004), measuring both self-regulation behaviors and creative cognitive processes.

Other aspects of self-regulation may also be addressed. We focused on planning and organization of work, but emotion regulation may also be considered, that may lead to problems such as conflict.

The role of self-efficacy in creative work may be studied by means of longitudinal research designs. This may help to unravel the dynamic relationships between self-efficacy and possible antecedents and outcomes in the field of design work. Business-related self-efficacy should be included to complement the model, providing a more balanced view on both domains in which creative professionals may be successful.

Another interesting avenue for future research may also be to distinguish entrepreneurial creatives versus those working as employees. Of course, generalization to other types of creative professions would also be an important issue to investigate further. It would be worthwhile to find out whether business aspects may overrule design work at some point in a career. We found the time investment in what may be considered the core of the job, architectural design, quite low, but perhaps this is common in creative professions. For example, fashion designers or industrial designers, have similar domains in which the creative domain may become overshadowed by business aspects. Although these roles may also be typically divided between individuals in a team, balancing them as individuals is an important topic to study in the future.

\section{Practical Implications}

Practical implications may be drawn from our findings on self-regulation in creative work. First, for selection purposes, self-regulation may be seen as an additional desirable characteristic for designers that are responsible for combining design work and business. Possibly, some natural selection 
may have taken place during the education of creative professionals, but within our sample of architects, there was still considerable variation, and those who indicated that selfregulation was higher, also indicated they were more successful.

Second, designers may be able to train skills related to self-regulation. These may involve time management skills, for example. Time management training involves self-regulation and is usually built quite broadly including hints and tips to organize work, but also how to make a realistic planning, learning to build in time for slack or for relaxation. A review of time management studies provides a cautious positive indication of the usefulness of time management (Claessens, Van Eerde, Rutte, \& Roe, 2007). Another area, not specifically addressed in this study, but also self-regulation may also include the personal management of emotional states and problem behaviors that can have a negative spillover on work performance. Third, organizations may help professionals to develop self-efficacy through success experiences. This means that challenging and new tasks can be trained, and initiatives from employees be encouraged. Bandura (2000) is an excellent source for more specific guiding principles and applications, providing details on techniques such as instructive modeling and guided skill perfection.

Overall, this study showed that self-regulation and design self-efficacy are important in studying both the creative and business-related roles in creative jobs.

Acknowledgments We thank Rutger van den Hurk from the Organization of Dutch Architects (BNA) for his help in data collection and Eric van der Geer for his suggestions during the preparation of this manuscript.

Open Access This article is distributed under the terms of the Creative Commons Attribution Noncommercial License which permits any noncommercial use, distribution, and reproduction in any medium, provided the original author(s) and source are credited.

\section{References}

ABF Research Kwartaalbericht Q1. (2008). Retrieved June 24, 2010, 2010, from http://www.abfresearch.nl/media/6866/kwartaalbericht 2008nr01_definitief.pdf.

Amabile, T. M. (1988). A model of creativity and innovation in organizations. Research in Organizational Behavior, 10, 123-167.

Amabile, T. M. (1996). Creativity in context. Oxford, UK: Westview Press.

Amabile, T. M., Schatzel, E. A., Moneta, G. B., \& Kramer, S. J. (2004). Leader behaviors and the work environment for creativity: Perceived leader support. Leadership Quarterly, 15(1), 5-32. doi:10.1016/j.leaqua.2003.12.003.

Bandura, A. (1977). Self-efficacy: Toward a unifying theory of behavioral change. Psychological Review, 84(2), 191-215. doi:10.1037/0033-295X.84.2.191.
Bandura, A. (1982). Self-efficacy mechanisms in human agency. American Psychologist, 37(2), 122-147. doi:10.1037//0003066X.37.2.122.

Bandura, A. (1991). Social cognitive theory of self-regulation. Organizational Behavior and Human Decision Processes, 50(2), 248-287. doi:10.1016/0749-5978(91)90022-L.

Bandura, A. (2000). Cultivate self-efficacy for personal and organizational effectiveness. In E. A. Locke (Ed.), The Blackwell handbook of principles of organizational behavior (pp. 120-136). Oxford: Blackwell.

Baruch, Y. (1999). Response rate in academic studies: A comparative analysis. Human Relations, 52(4), 421-438. doi:10.1177/ 001872679905200401.

Britton, B. K., \& Glynn, S. M. (1989). Mental management and creativity: A cognitive model of time management for intellectual productivity. In J. A. Glover, R. R. Ronning, \& C. R. Reynolds (Eds.), Handbook of Creativity (pp. 429-440). New York: Plenum Press.

Carver, C. S., \& Scheier, M. F. (1998). On the self-regulation of behavior. Cambridge: University Press.

CBS. (2010). Statistisch Jaarboek, p. 122. http://www.cbs.nl/nl-NL/ menu/publicaties/boeken/statistisch-jaarboek/archief/2010/2010statistisch-jaarboek-2010-pub.htm.

Claessens, B. J. C. (2004). Perceived control of time: Time management and personal effectiveness at work. Dissertation Eindhoven University of Technology.

Claessens, B. J. C., Van Eerde, W., Rutte, C. G., \& Roe, R. A. (2004). Planning behavior and perceived control of time at work. Journal of Organizational Behavior, 25(8), 937-950. doi:10.1002/job.292.

Claessens, B. J. C., Van Eerde, W., Rutte, C. G., \& Roe, R. A. (2007). A review of the time management literature. Personnel Review, 36(2), 255-276. doi:10.1108/00483480710726136.

Cools, E., \& Van den Broeck, H. (2007). Development and validation of the Cognitive Style Indicator. The Journal of Psychology: Interdisciplinary and Applied, 141(4), 359-387. doi:10.3200/ JRLP.141.4.359-388.

Cropley, A. J. (1999). Definitions of creativity. In M. A. Runco \& S. R. Pritzker (Eds.), Encyclopedia of creativity (Vol. 1) (pp. 511-524). London: Academic Press.

DeFillippi, R., Grabher, G., \& Jones, C. (2007). Introduction to paradoxes of creativity: Managerial and organizational challenges in the cultural economy. Journal of Organizational Behavior, 28(5), 511-521. doi:10.1002/job.466.

Deming, W. E. (2000). The new economics for industry, government, education (2nd ed.). Cambridge, MA: MIT Press.

Dey, E. L. (1997). Working with low survey response rates: The efficacy of weighting adjustments. Research in Higher Education, 38(2), 215-227. doi:10.1023/A:1024985704202.

Diamond, R., \& Moezzi, M. (2002). Becoming allies: Combining social science and technological perspectives to improve energy research and policy making. Lawrence Berkeley National Laboratory. http://escholarship.org/uc/item/2zc1w00p.

Feist, G. J. (1998). A meta-analysis of personality in scientific and artistic creativity. Personality and Social Psychology Review, 2(4), 290-309. doi:10.1207/s15327957pspr0204_5.

Fleck, J. I., \& Weisberg, R. W. (2004). The use of verbal protocols as data: An analysis of insight in the candle problem. Memory \& Cognition, 32(6), 990-1006. doi:10.3758/BF03196876.

Flew, T., \& Cunningham, S. (2010). Creative industries after the first decade of debate. The Information Society, 26(2), 113-123. doi: $10.1080 / 01972240903562753$.

Goldschmidt, G. (1991). The dialectics of sketching. Creativity Research Journal, 4(2), 123-143. doi:10.1080/10400419109534381.

Goldschmidt, G. (1999). Design. In M. A. Runco \& S. R. Pritzker (Eds.), Encyclopedia of creativity (Vol. 1) (pp. 525-535). New York: Academic Press. 
Gong, Y., Huang, J. C., \& Farh, J. L. (2009). Employee learning orientation, transformational leadership, and employee creativity: The mediating role of employee creative self-efficacy. The Academy of Management Journal (AMJ), 52(4), 765-778.

Green, K. E., Boser, J. A., \& Hutchinson, S. R. (1998). Response-rate differences and response-enhancement effects by population type. Psychological Reports, 83(1), 336-338. doi:10.2466/ PR0.83.5.336-338

Hargadon, A. B., \& Bechky, B. A. (2006). When collections of creatives become creative collectives: A field study of problem solving at work. Organization Science, 17(4), 484-500. doi: $10.1287 /$ orsc. 1060.0200 .

Hayes, J., \& Allinson, C. W. (1998). Cognitive style and the theory and practice of individual and collective learning in organizations. Human Relations, 51(7), 847-871.

Hennessey, B. A., \& Amabile, T. M. (2010). Creativity. Annual Review of Psychology, 61(1), 569-598. doi:10.1146/ annurev.psych.093008.100416.

Isaksen, S. G., Dorval, K. B., \& Treffinger, D. J. (2000). Creative approaches to problem solving (2nd ed.). Dubuque, IA: Kendell/ Hunt.

Isaksen, S. G., \& Treffinger, D. J. (2004). Celebrating 50 years or reflective practice: Versions of creative problem solving. Journal of Creative Behavior, 38(2), 75-101.

Jaussi, K. S., Randel, A. E., \& Dionne, S. D. (2007). I am, I think I can, and I do: The role of personal identity, self-efficacy, and cross-application of experiences in creativity at work. Creativity Research Journal, 19(2), 247-258.

Jöreskog, K. G., \& Sörbom, D. (2007). Lisrel 8.80. Chicago: Scientific Software International, Inc.

Judge, T. A., \& Bono, J. E. (2001). Relationship of core selfevaluations traits-self-esteem, generalized self-efficacy, locus of control, and emotional stability - with job satisfaction and job performance: A meta-analysis. Journal of Applied Psychology, 86(1), 80-92.

Kirton, M. (1976). Adaptors and innovators. Journal of Applied Psychology, 61, 622-629. doi:10.1037/0021-9010.61.5.622.

Kirton, M. (Ed.). (1994). Adaptors and innovators: Styles of creativity and problem solving. London: Routledge.

Ling, Y. (2003). A conceptual model for selection of architects by project managers in Singapore. International Journal of Project Management, 21(2), 135-144.

Locke, E. A., \& Latham, G. P. (1990). A theory of goal setting and task performance. New Jersey: Prentice-Hall.

Lord, R. G., Diefendorff, J. M., Schmidt, A. M., \& Hall, R. J. (2010). Self-regulation at work. Annual Review of Psychology, 61(1), 543-568. doi:10.1146/annurev.psych.093008.100314.

Mathieu, J. E., \& Taylor, S. R. (2006). Clarifying conditions and decision points for mediational type inferences in organizational behavior. Journal of Organizational Behavior, 27(8), 1031-1056. doi:10.1002/job.406.

Miron, E., Erez, M., \& Naveh, E. (2004). Do personal characteristics and cultural values that promote innovation, quality, and efficiency compete or complement each other? Journal of Organizational Behavior, 25(2), 175-199. doi:10.1002/job.237.

Osburn, H. K., \& Mumford, M. D. (2006). Creativity and planning: Training interventions to develop creative problem-solving skills. Creativity Research Journal, 18(2), 173-190.

Oyedele, L. O., \& Tham, K. W. (2007). Clients' assessment of architects' performance in building delivery process: Evidence from Nigeria. Building and Environment, 42(5), 2090-2099. doi:10.1016/j.buildenv.2005.06.030.
Peeters, M. A. G., Van Tuijl, H. F. J. M., Reymen, I. M. M. J., \& Rutte, C. G. (2007). The development of a design behaviour questionnaire for multidisciplinary teams. Design Studies, 28, 623-643. doi:10.1016/j.destud.2007.06.004.

Redmond, M. R., Mumford, M. D., \& Teach, R. (1993). Putting creativity to work: Effects of leader-behavior on subordinate creativity. Organizational Behavior and Human Decision Processes, 55(1), 120-151. doi:10.1006/obhd.1993.1027.

Reymen, I. M. M. J., Hammer, D. K., Kroes, P. A., Van Aken, J. E., Dorst, K., Bax, M. F. T., et al. (2006). A domain-independent descriptive model and its application to structured reflection on design processes. Research in Engineering Design, 16(4), 147-173. doi:10.1007/s00163-006-0011-9.

Schyns, B., \& Von Collani, G. (2002). A new occupational selfefficacy scale and it's relation to personality constructs and organizational variables. European Journal of Work and Organizational Psychology, 11, 219-241. doi:10.1080/ 13594320244000148.

Shalley, C. E., Zhou, J., \& Oldham, G. R. (2004). The effects of personal and contextual characteristics on creativity: Where should we go from here? Journal of Management, 30(6), 933-958. doi:10.1016/j.jm.2004.06.007.

Sonnentag, S. (1998). Expertise in professional software design: A process study. Journal of Applied Psychology, 83(5), 703-715. doi:10.1037/0021-9010.83.5.703.

Stajkovic, A. D., \& Luthans, F. (1998). Self-efficacy and work-related performance: A meta-analysis. Psychological Bulletin, 124(2), 240-261. doi:10.1037//0033-2909.124.2.240.

Thompson, P., Jones, M., \& Warhurst, C. (2007). From conception to consumption: Creativity and the missing managerial link. Journal of Organizational Behavior, 28(5), 625-640. doi: $10.1002 /$ job.465.

Tierney, P., \& Farmer, S. M. (2002). Creative self-efficacy: Its potential antecedents and relationship to creative performance. Academy of Management Journal, 45(6), 1137-1148. doi: $10.2307 / 3069429$.

Tierney, P., \& Farmer, S. M. (2004). The Pygmalion process and employee creativity. Journal of Management, 30(3), 413-432. doi:10.1016/j.jm.2002.12.001.

Tripoli, A. M. (1998). Planning and allocating: Strategies for managing priorities in complex jobs. European Journal of Work and Organizational Psychology, 7, 455-476. doi:10.1080/ 135943298398501.

Tschang, F. T. (2007). Balancing the tensions between rationalization and creativity in the video games industry. Organization Science, 18(6), 989-1005. doi:10.1287/orsc.1070.0299.

Tsui, A. S., \& Ashford, S. J. (1994). Adaptive self-regulation: A process view of managerial effectiveness. Journal of Management, 20(1), 93-121. doi:10.1177/014920639402000105.

Unsworth, K. L. (2001). Unpacking creativity. Academy of Management Review, 26(2), 289-297.

Van Oorschot, K. E., Bertrand, J. W. M., \& Rutte, C. G. (2005). Field studies into the dynamics of product development tasks. International Journal of Operations \& Production Management, 25(8), 720-739. doi:10.1108/01443570510608574.

Vancouver, J. B., \& Day, D. V. (2005). Industrial and organization research on self-regulation: From constructs to applications. Applied Psychology-an International Review-Psychologie Appliquee-Revue Internationale, 54(2), 155-185. doi:10.1111/ j.1464-0597.2005.00202.x. 